\title{
Effect of intralesional bleomycin as an alternative therapy for cystic hygroma \\ AK Saha ${ }^{1}$, SS Haque ${ }^{2}$, KMS Islam ${ }^{3}$
}

\begin{abstract}
Cystic hygroma is a congenital malformation of the lymphatic system. Surgical excision is the treatment of choice, but injection of a sclerosing agent into the cyst is an alternative procedure. The aim of this study was to review the efficacy of intralesional bleomycin injection in cystic hygroma. This study was carried out in a private clinic in Khulna over a period of 2 years on 7 patients. Bleomycin at a dosage of $0.4-0.6 \mathrm{mg} / \mathrm{kg}$ was injected into the cyst and repeated injection was given at an interval of 4-8 weeks. Clinical outcomes were reviewed and analyzed. Seven patients, 4 males and 3 females, aged between one month and 4 years were treated with intralesional bleomycin injections. Complete clinical resolution was obtained in 6 cases (86\%). Mass reduction was noted in 1 (14\%) patient. Adverse reactions including mild fever, local swelling, redness and pain at the site of injection occurred in 3 cases (43\%). These reactions persisted for only a few days. Transient systemic side effect like vomiting noted in one patient. So intralesional bleomycin injection is a safe and effective alternative to the surgical treatment of cystic hygroma.
\end{abstract}

Bang Med J Khulna 2013; $46: 12-15$

\section{Introduction}

Cystic hygroma is a multiloculated congenital malformation of the lymphatic system occurring in approximately 1 in 6000-12000 births. ${ }^{1}$ In 1843, Wernher reported the first case of cystic hygroma. This term comes from the Greek word "hygroth" meaning fluid and "oma" meaning tumor. ${ }^{2}$ Most cystic hygromas are evident at birth (50-65\%), while the remainder evident by the time the individual is aged 2 years. ${ }^{3}$ The lesion occurs with approximately equal frequency in boys and girls. 4 The cause likely is related to events that occur during the development of the lymphatic system in which the primitive lymphatic sac fail to establish communication with developing venous system. Hygromas usually reside in close proximity to large veins and lymphatic ducts, in neck (75\%), axilla (20\%) and others (5\%) e.g. mediastinum, retroperitonium, pelvis and groin. ${ }^{5}$

It can lead to morbidity because of cosmesis, compression of adjacent organs (i.e. respiratory obstruction, dysphagia, nerve compression and malocclusion) or can result in local inflammation, infection, sinus formation and hemorrhage. Most of the cystic hygromas are clinically obvious and require no imaging studies for diagnosis. The investigations are done to assess its extension into the surrounding structures.6-7 Spontaneous resolution occurs infrequently. Surgical excision is the treatment of choice but it is very difficult in some cases because of infiltrative nature of the thin walled multiple cysts to the surrounding tissues. Complications (12-23\%) and recurrences (15-53\%) commonly occur after surgery. ${ }^{11-18}$ Risks of surgical removal of lymphangioma include vital organ injuries, bleeding, infection and scar formation. Alternative treatments such as radiation therapy and injection of sclerosing agents had been tried but the results were not satisfactory. ${ }^{7-8}$

In recent years, two sclerosing agents, bleomycin and OK-432, have been favoured by some surgeons for the treatment of cystic hygroma. ${ }^{12,14,15}$ Yura in 1977 was the first clinician to use bleomycin solution as a sclerosing agent for treatment of cystic hygroma. ${ }^{7}$ Presentation of a standard article needs usually atleast 30 cases. Cystic hygroma is not so common and several international publications reported 10 cases within 2 years, 11 and 12 cases study over 3 years. ${ }^{2,16,17}$ So study of 30 cases may need about 10 years.

1. Amar Kumar Saha FCPS, Associate Professor of Pediatric Surgery, Khulna Medical College, Khulna

2. Shaikh Sayidul Haque FRCS, Professor of Surgery, Khulna Medical College, Khulna

3. KM Saiful Islam MBBS, Asstt. Registrar of Paediatric Surgery, KMCH, Khulna 
The aim of this study was to review the efficacy of intralesional bleomycin injection in cystic hygroma. This study was done to assess the results of intralesionai bleomycin as it is simple, less expensive and requires no exhaustive technique and expertise as compared to the surgical excision.

\section{Materials and Method}

This prospective case study was carried out in a private clinic in Khulna over a period of 2 years from July 2010 to June 2012. Guardian of all patients of cystic hygroma was explained about intralesiona! bleomycin therapy. Those who agreed were included in this study. The patients were admitted for twenty four hours. A standardized data collection sheet recorded the patient's details

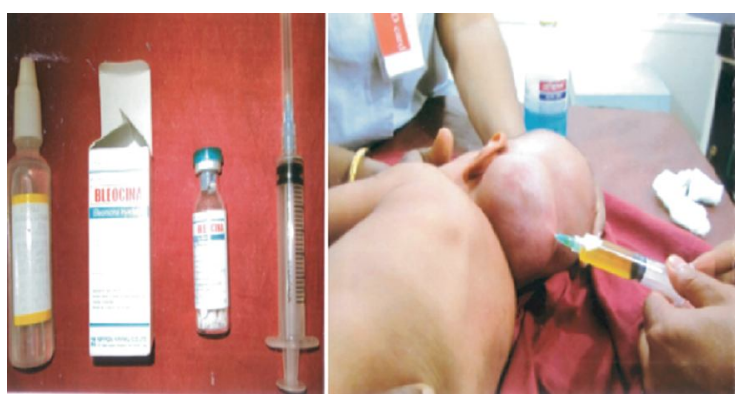

Figure-1. Method of intralesional bleomycin injection

including age, sex, weight, size and location of lesion, clinical history, bleomycin dose, clinical response, side effects and follow-up. Colour photographs were taken of every patient before and after completion of treatment. Total number of study population was 7 . The parents of the patient were counseled and results of the therapy explained to them. Informed consent was taken to the use of bleomycin as intralesional injection therapy. Bleomycin powder (15 mg) was reconstituted with $15 \mathrm{ml}$ of normal saline (dilution $1 \mathrm{mg} / \mathrm{mi}$ ). The calculated dose of bleomycin was taken from the reconstituted bleomycin and diluted in 5-10 ml normal saline. Cyst content was aspirated aseptically with a 10 cc disposable syringe (Fig-1) and aspiration continued placing the needle in situ till maximum evacuation of the content. Required amount was measured on the basis of weight of the child and cyst size. Prepared

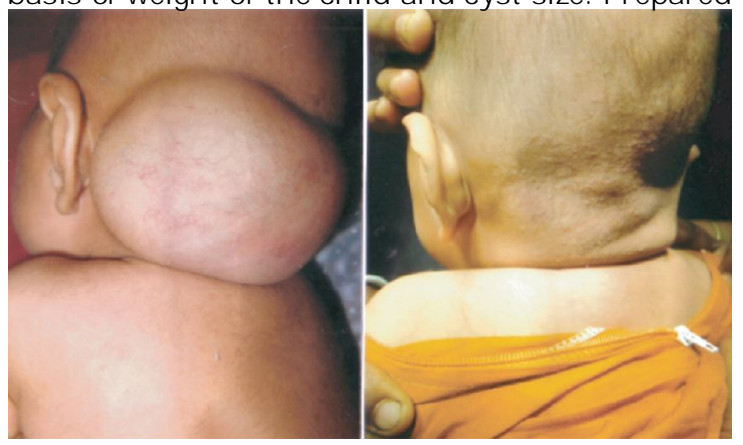

Figure-2. Before and after intralesional bleomycin bleomycin solution at a dosage of $0.4-0.6 \mathrm{mg} / \mathrm{kg}$ was injected into the cyst after aspiration. Only one child needed general anesthesia. All the patients were observed for 24 hours to note and treat any immediate problems like fever and pain. Mild fever, swelling, and pain at the injection site disappeared within 24-48 hours. Patients were discharged and asked to come after 4 weeks for follow up. On follow up visit, the size of the cystic hygroma was measured and compared with the pre-injection size. Repeated injections were tried at an interval of 4-8 weeks. Monthly follow up was routinely conducted upto 3 months after completion of planned intralesional injection. Clinical outcomes were reviewed and analyzed.

\section{Results}

Out of seven patients, 4 were males and 3 females. Age variation was between one month and 4 years.

Table I

Case summary at a glance

\begin{tabular}{cccc}
\hline $\begin{array}{c}\text { Case Age } \\
\text { No (months) }\end{array}$ & $\begin{array}{c}\text { Site } \\
\text { (neck) }\end{array}$ & $\begin{array}{c}\text { No. of } \\
\text { injection }\end{array}$ & $\begin{array}{c}\text { Side effect } \\
\text { (dose) }\end{array}$ \\
\hline
\end{tabular}

\begin{tabular}{ccccc}
\hline 1 & 5 & Posterior triangle & 4 & Nil \\
2 & 1 & Posterior triangle & 4 & $\begin{array}{c}\text { Redness and } \\
\text { Mild fever } \\
\text { (2nd, 3rd) } \\
\end{array}$ \\
3 & 11 & Posterior triangle & 3 & Vomiting (1st) \\
4 & 18 & Posterior triangle & 4 & Nil \\
5 & 12 & Posterior triangle & 3 & local swelling \\
& & & & \& redness(3rd) \\
6 & 36 & Posterior triangle & 2 & Mil \\
7 & 48 & Posterior triangle & 4 & $\begin{array}{c}\text { Pain and } \\
\end{array}$ \\
& & and mediastinum & & swelling $(1,2,3)$ \\
\hline
\end{tabular}

Among them 5 was infant and rest of 2 was above one year of age. All but one presented due neck swelling and cosmetic disfiguration. Elderly child of this study had extension of cystic hygroma into right mediastinum and difficulty in breathing since birth. Complete resolution (Table II) was obtained in 6 cases (86\%) and mass reduction was noted in $1(14 \%)$.

\section{Table II}

Outcome of intralesional leomycin therapy

\begin{tabular}{lccc}
\hline Sex distribution & $\begin{array}{c}\text { Complete } \\
\text { resolution }\end{array}$ & Size reduction & Total (\%) \\
\hline Male & 3 & 1 & $4(57)$ \\
Female & 3 & 0 & $3(43)$ \\
Total $(\%)$ & $6(86)$ & $1(14)$ & $7(100)$ \\
\hline
\end{tabular}

One patient needed 2 doses, 2 patients 3 doses and rest of 4 cases were injected with 4 doses of intralesional bleomycin. Adverse reactions 
including mild fever, local swelling, redness and pain at the site of injection occurred in 3 cases (43\%). These reactions persisted for only a few was days. Transient systemic side effect like vomiting noted in one patient. No significant adverse effect was found on 3 months follow up.

\section{Discussion}

Lymphangioma is a common developmental anomaly of the lymphatic system. Majority of lymphangiomas occur in the head and neck area. ${ }^{5}$ In our study cystic hygroma was in posterior triangle in all 7 cases. Size and age of presentation was variable but all lesions were present since birth. Male-female ratio was 4:3. This approximate equal frequency in boys and girls was also observed by Koichi Tanaka et $\mathrm{al}^{4}$. Landing and Farber 18 classified lymphangioma into 3 groups (1) iymphangioma simplex, composed of small capillary-sized thin walled lymphatic channels; (2) cavernous lymphangioma, comprising dilated lymphatic channels; and (3) cystic lymphangioma or cystic hygroma, consisting of multiple cystic cavities filled with straw coloured fluid. The treatment of cystic hygroma is a challenging problem both for the parents and surgeons as both expect an earlier and more effective treatment of this problematic pathological lesion.7,14 Surgical excision offers the best opportunity for permanent cure of cystic hygroma. The goal is to excise the lesion completely sparing all vital neurovascular structures. If the lesion is not completely excised, then recurrence is common. Most of the advanced pediatric surgical centers in Bangladesh prefer sclerotherapy (bleomycin and OK-432) to surgical excision. 19

We preferred bleomycin as a sclerosant because of its easy availability, low cost, and minimal side effects when used in low dose intralesionally in cystic hygroma. Bleomycin was discovered as an antibiotic in 1965 by Dr. Umezawa. Interestingly, it has never been used as an antibiotic after it was found to cause incision of single stranded DNA. ${ }^{20}$

In our study intralesional bleomycin therapy was effective in complete resolution of cystic hygroma in $86 \%$ of children. These results were in agreement with those reported by Tanaka (87\%), Okada (86\%), Baskin D (70\%), Muir T (80\%), Ikram Ud Din (75\%) and Zuifiqar (88\%), Chakrabarty (78\%).4,6,12,13,17,21,22 The most important factor in intralesional bleomycin is the concentration of the sclerosant available to the endothelial lining of the cystic hygroma. In lesions that are aspirated completely the bleomycin available per unit area of the lesion is higher and so is its sclerosing effect. 23

The reduction of mass size was observed in one child. About 60\% mass reduction was noted after
4 doses of intralesional bleomycin. A few extra words needed to introduce this child. Cystic hygroma of neck was diagnosed by prenatal sonology and developed respiratory distress soon after birth. Subsequent chest X-ray and CT scan revealed extension into right side of thorax and contained both cystic and solid components. Parents sought surgical treatment both at home and abroad because he could not sleep in normal supine position due to respiratory distress. But all specialized centres were in favour of wait and see approach after explaining the possible hazard of planned heroic surgery. Initially this huge swelling was cystic but during the beginning of intralesional bleomycin therapy at the age of 4 years, the accessible part of the cyst was partly cystic and partly solid. Intralesional bleomycin therapy is more effective for cystic lymphangiomas. 17 This was also observed in our study. Therefore, the patient selection for this mode of therapy is important.

Minor side effects of bleomycin like local swelling, redness, pain and low-grade fever were noted after injection in $43 \%$ cases in our study, mostly recovered within 24-48 hours which was very similar $(42.9 \%)$ to Niramis $R$ et al in their large series. ${ }^{24}$

Pulmonary toxicity is a potential side effect of bleomycin therapy. This risk is related to the dose, an increasing incidence being associated with the total dose of more than 400 units or a single dose exceeding $30 \mathrm{mg} / \mathrm{m} 2$ of body surface area. The pulmonary fibrosis of intralesional bleomycin therapy is not reported so far because of its low dose. ${ }^{17}$ Even the use of bleomycin as a sclerosant in the intrauterine fetus with cystic hygroma is under trial and some have noticed promising results. 5,15

\section{Conclusion}

Our study concludes that intra-lesional Bleomycin as sclerosant appears to be a safe and effective alternative to surgical treatment of cystic hygroma. However, intralesional bleomycin therapy is simple and less expensive. It does not require exhaustive technique and expertise as compared to the surgical excision. So, it may be suitable for use as primary therapy to avoid the risk of inadvertent damage by surgery as well as for cosmetic reasons.

\section{References}

1 Mirza B, Ijaz L. Saleem M, Sharif M, Sheikh A. Cystic hygroma : An overview. J Cutan Aesthet Surg. 2010; 3: 139-44.

2 Mathur NN, Rana, Bothra R, Dhawan R, Kathuria G, Pradhan T. Bieomycin Sclerotherapy in congenital lymphatic and vascular malformation of 
head and neck. Int $\mathrm{J}$ Pediatr Otorhinolaryngol. 2005; 69(1): 75-80.

3. Chappuis JP. Current aspects of cystic lymphangioma in the neck Arch Pediatr. 1994 ; 1(2): 186-92

4. Tanaka K et al. Sclerosing therapy with bleomycin emulsion for lymphangioma in children. Pediatr Surg Int!. 1990; 5 (4): 270-3.

5. Kennedy TL, Whitaker M, Pellitteri P, Wood WE. Cystic hygroma/lymphangioma: a rational approach to management. Laryngoscope. 2001; 111: 1929-37.

6. Baskin D, lander B, Bankaoglu M. Local bleomycin injection in the treatment of lymphangioma. Eur $\mathrm{J}$ Pediatr Surg. 2005; 15 (6): 383-6.

7. Yura J, Hasshimoto T, Tsuruga N et al. Bleomycin treatment for cystic hygroma in children. Arch Jap Chir 1977; 5 (46): 607-14.

8. Kennedy TL. Cystic hygroma-lymphangioma: a rare and still unclear entity. Laryngoscope. 1989; 99: 1-10.

9. Ninh TN. Cystic hygroma in children: a report of 126 cases. J Pediatr Surg 1974; 9: 191-5.

10. Chait D. Management of cystic hygromas. Surg Gynecol Obstet 1974; 139: 55-8.

11. Charabi B, Bretlau P, Bille M, Holmelund M. Cystic hygroma of the head and neck-a long-term followup of 44 cases Acta Otolaryngol Suppl. 2000; 543: 248-50.

12. Okada A, Kubota A, Fukuzawa M, Imura K, Kamata S. Injection of beomycin as a primary therapy of the cystic lymphangioma. $J$ Pediatr Surg. 1992; 27(4): 440-3.

13. Zulfiqar MA, Zelha AM, Zakria Z, Amin T. The treatment of neck lymphangioma with intralesional injection of bleomycin. Med J Malaysia. 1999; 54 (4): 478-81.
14. Ogita S, Tsuto T, Deguchi E, et al. Ok-432 therapy for unresectable lymphangioma in children. $\mathrm{J}$ Pediatr Surg 1991; 26: 263-70.

15. Sichei JY, Udassin R, Gozal D, Koplewitz BZ, Dano I, Eliashar R: OK-432 therapy for cervical lymphangioma. Laryngoscope 2004; 114: 1805-9

16 Sichel JY, Udassin R, Gozal D, Koplewitz BZ, Dano I, Eliashar R. OK-432 therapy for cervical lymphangioma. Laryngoscope. 2004 Oct; 114(10): 1805-9.

17. Ikram Ud Din. Inayat-ur-Rehman, Rasool G, Khan AR, Shah e Din. Intralesional bleomycin therapy of cystic hygroma in children. J Med Sci. 2008, 16(2): 87-90. 18 Landing BH, Farber S. Tumors of the cardiovascular system. Atlas of tumor pathology. Washington, DC: Armed Forces Institute of Pathology 1956.

19. Personal communication with department of pediatric surgery, BSMMU, DSH, DMCH, $\mathrm{CMCH}$

20. Umezawa H, Maeda K, Takeuchi T, Okami Y. New antibiotics, bleomycin A and B. J Antibiot 1966; 19(5): 200-9.

21. Chakrabarty AK. Role of bleomycin as a primary therapy for cystic hygroma in children. MS thesis, Dhaka University. July 2003: 37

22. Muir T, Kirsten M, Kirsten M, Fourie P, Doppinar $\mathrm{N}$, lonescu GO. Intralesional bleomycin injection (IBI) treatment for haemangiomas and congenital vascular malformations. Pediatr Surg Int. 2004; 19 (12): 766-73.

23. Gallaghar PG, Mahoney MJ, Gosche JR: Cystic hygroma in the fetus and newborn. Semin PerinatoM999; 23: 341-56.

24. Niramis R, Watanatittan S, Rattanasuwan $T$. Treatment of cystic hygroma by intralesional bleomycin injection: experience in 70 patients. Eur J Pediatr Surg. 2010; 20(3): 178-82 